\title{
Evaluation and Selection Model of Strategic Emerging Industries in Guangdong Province of China Based on AHP-TOPSIS
}

\author{
Jun-ru Chen ${ }^{1}, \mathrm{He} \mathrm{Nie}^{2} \&$ Kai-long $\mathrm{Li}^{1}$ \\ ${ }^{1}$ International Business School, Jinan University, Zhuhai, China \\ ${ }^{2}$ College of Economics, Jinan University, Guangzhou, China \\ Correspondence: Xue-Jun Lin, International Business School, Jinan University, 519070, Zhuhai, China. E-mail: \\ tlxj@jnu.edu.cn
}

Received: August 25, 2015

doi:10.5539/ijbm.v10n11p161
Accepted: September 11, 2015

Online Published: October 28, 2015

URL: http://dx.doi.org/10.5539/ijbm.v10n11p161

\begin{abstract}
Considering the regional characteristics of strategic emerging industries, we proposed a strategic emerging industry selection model based on AHP-TOPSIS and used the model to do a comprehensive evaluation in order to achieve a development selection of strategic emerging industries of a certain region. We build the industrial competitiveness evaluation indicator system based on technological innovation perspective, and then we use analytic hierarchy process (AHP) to make indicators empowerment. Finally, we use TOPSIS method to evaluate strategic emerging industries in Guangdong Province of China. Instance analysis shows that the basic conclusions are identical with the actual status quo in Guangdong, and it verifies the validity and rationality of the model.
\end{abstract}

Keywords: selection, strategic emerging industries, AHP-TOPSIS

\section{Introduction}

Strategic emerging industry is the industry collection refers to the advanced technology, which plays an important role in the national economy, and it has the influence on other industries. It can grow into a pillar industry in the future but the industry is still in the incubation period and growth period (M, 2014). Its rise can be expected to gradually become a new economic growth point in the future. Compared with the traditional industries, the high-growth, innovative, driven and persistent of emerging industries of strategic will promote sustainable development of the national economy (Ou, 2011). In the selection of strategic emerging industries should be considered on the national will and policy support, and we should focus on the leading role effect of industries and technology spillover effect of strategic emerging industries. It is necessary to consider the current output value target, but also pay attention to the long-term industrial technology upgrading goals (Guo, 2011).

In terms of the definition and characteristics of strategic and emerging industries, Wan (2010) stressed the strategic emerging industry is different from the "innovative" features of other industries; Zhu (2010) emphasized the important significance of strategic emerging industries in the national economy and industrial structure restructuring. Li et al. (2013) supposed that the scientific and technological innovation promote the development of strategic emerging industries, therefore, they stressed the importance of technological innovation in strategic emerging industry.

In terms of evaluation indicator research in strategic emerging industries, $\mathrm{He}$ et al. (2011) believed that the indicator selection of strategic emerging industries should reflect the four characteristics, which refers to the overall industry, industry leading and industry association, industry dynamics; Sun (2011) believed that the development of emerging industries should include nature, economic, social and human, technological, industrial competitiveness and the government of six aspects of select targets; Zhang et al. (2010) thought that we should consider carefully to select the indicators in respective of policy-oriented, economic effects, innovation, development potential.

In the evaluation of strategic emerging industries, He et al. (2010) uses fuzzy comprehensive evaluation method to evaluate the emerging strategic industries; Zhang et al. (2010) used the method of gray correlation analysis on emerging strategic industries to evaluate; Qiao (2010) used industry contribution and the industry regional competitiveness as horizontal and vertical coordinates, drawing policy guidance to establish strategic emerging 
industries matrix selection model.

In summary, based on previous research, we construct a model of AHP-TOPSIS to do a selection and evaluation research. AHP is a decision method for a common species of qualitative and quantitative, and TOPSIS method is a common and effective method in a multi-objective decision analysis, this paper attempts to combine AHP and TOPSIS, through a combination of empowerment methods to establish the strategic emerging industry selection evaluation system, and the use TOPSIS to effectively evaluate and select strategic emerging industries of Guangdong province.

\section{Establishment of the Evaluation and Selection Model}

\subsection{The Determination of Indicator Weights via AHP}

AHP, put forward by Saaty in the 1970s, calls for a hierarchical structure. The hierarchical structure generally contains three sections.

Target hierarchy: the target that we want to achieve.

Criterion hierarchy: the factors that can affect the achievement of target.

Measure hierarchy: the scheme that is available.

Judgment matrix, $A=\left(a_{i j}\right)_{m \times n}$, is constructed according to the 1-9 scale method. The weights and maximum eigenvalue, calculated by judgment matrix, are used to figure out the consistency index, $C I$,

$$
C I=\frac{\lambda_{\max }-n}{n-1}
$$

$R I$, is determined with the order of matrix $n$

$$
C R=\frac{C I}{R I}
$$

Only when $C R<0.1$, can the judgment consistency matrix be accepted, that is, the weights can be employed.

\subsection{TOPSIS Method}

TOPSIS is proposed by Huang et al. (1981), which is an excellent evaluation method. The basic idea is: comprehensive evaluation problem is transformed into gaining the differences between each evaluated object-"distance". That is, be in the normalized data matrix to find the optimal goal and the worst goal and determine the positive ideal solution and the negative ideal solution, then to calculate the distance between each evaluation object and the ideal solution and also the negative ideal solution, and comparing to get comprehensive evaluation rankings. Concrete steps of TOPSIS method are as follows (He et al., 2014):

Step 1: Polarity process evaluation indicators to obtain polarity consistent matrix, due to the indicators data of this paper are all very large indicators, it may not be processed.

Step 2: Normalize the evaluation indicators through the range transformation method, the normalized matrix $X=\left(x_{i j}\right)_{m \times n}$ is:

$$
x_{i j}=\frac{r_{i j}-\min _{i}\left\{r_{i j}\right\}}{\max _{i}\left\{r_{i j}\right\}-\min _{i}\left\{r_{i j}\right\}}, i=1,2, \ldots m ; j=1,2, \ldots, n
$$

Where $r_{i j}$ is the value of the corresponding journal indicators, $x_{i j}$ is the dimensionless value, and also $x_{i j} \in[0,1], i=1,2, \ldots, m ; j=1,2, \ldots, n$.

Step 3: Construct a weighted decision matrix norms Z. Based on weight of each indicator, so $z_{i j}=w_{i j} x_{i j}, i=1,2, \ldots m ; j=1,2, \ldots, n$.

Step 4: Determine positive ideal solution $z^{+}$and negative ideal solution $z^{-}$. Suppose the $j$-th attribute value of positive ideal solution $z^{+}$is $z_{j}^{+}$, and the $j$-th attribute value of negative ideal solution $z^{-}$is $z_{j}^{-}$.

So, positive ideal solution and negative ideal solution are denoted by:

$z^{+}=\min _{i}\left\{z_{i j}\right\}, i=1,2, \ldots, m ; j=1,2, \ldots, n, \quad z^{-}=\max _{i}\left\{z_{i j}\right\}, i=1,2, \ldots, m ; j=1,2, \ldots, n$

Step 5: Separately calculate the distance between $i$-th evaluation object and ideal solution. $d_{i}^{+}$is the distance between $i$-th evaluation object and positive ideal solution $z^{+}$, and $d_{i}^{-}$is the distance between $i$-th evaluation 
object and negative ideal solution $z^{-}$:

$$
d_{i}^{+}=\sqrt{\sum_{j=1}^{4}\left(z_{i j}-z_{j}^{+}\right)^{2}}, i=1,2, \ldots, m, \quad d_{i}^{-}=\sqrt{\sum_{j=1}^{4}\left(z_{i j}-z_{j}^{-}\right)^{2}}, i=1,2, \ldots, m
$$

Step 6: Calculate relative comprehensive evaluation value of each object and rank them.

Comprehensive evaluation value for evaluation object is:

$$
b_{i}=\frac{d_{i}^{-}}{d_{i}^{+}+d_{i}^{-}}, i=1,2, \ldots, m
$$

Comprehensive evaluation value is between 0 and 1 , if the value is closer to 1 , indicating that the corresponding evaluation objects closer to the optimal level; conversely, the worst level.

Summarization above, we determine the weight of evaluation indicators of emerging industries via AHP, and we use TOPSIS method to have a comprehensive evaluation ranking, and further, select competitive industries to analyze. This is the establishment of the evaluation and selection model.

\section{Instance Analysis}

\subsection{Construction of Evaluation Index System of Emerging Industry}

This paper is based on the research results of a number of scholars. We ultimately concluded to regard technology innovation dimension, economic efficiency, knowledge efficiency, hardware support, software support those five dimensions as the index evaluation system through using Delphi method by the Guangdong Provincial Science and Technology Department (to easily describe, we use five dimensions for the short). The evaluation system is shown in Figure 1 as follows:

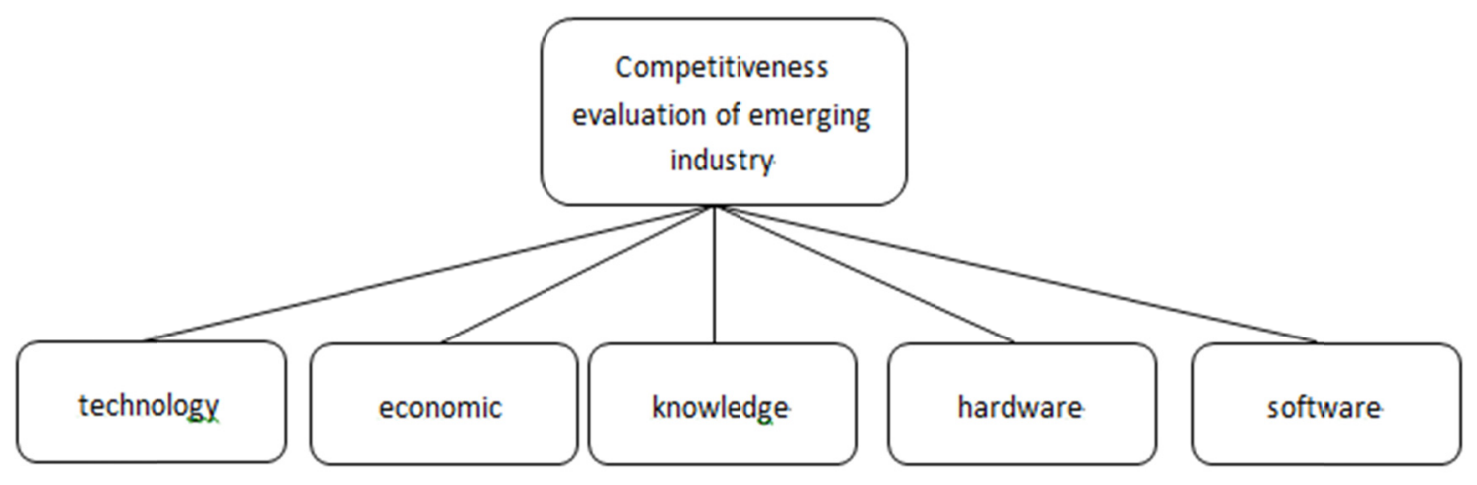

Figure 1. Evaluation index system of emerging industry

Among them, the technical innovation behavior refers to innovative knowledge and new technologies, new processes, new production methods and business model implementation process. Research development or technology combination is a manifestation of technological innovation behavior, without technological innovation behavior, the old products cannot be transformed into new products, new technology and new services. Current technology innovation behavior dimension, generally is measured by the investment of regional science and technology, industry science and technology personnel, government science and technology, scientific and technological cooperation. Economic efficiency and knowledge efficiency belong to the contents of the benefits of technological innovation. Because the technical innovation behavior is necessary condition to improve the competitiveness of emerging industries, technology innovation benefits can directly reflect the level of competitiveness of emerging industries. At present, we use emerging industry output value, sales income to measure the economic efficiency, and use increasing the annual amount of license number and trademarks number of famous brands to measure knowledge efficiency. Ability to support technological innovation is divided into hardware support and software support, it can promote or hinder emerging enhance industrial competitiveness to a certain extent. And the ability is mainly measured through the innovative platform, 
technology services and GDP.

\subsection{Collection and Collation of Data}

As the statistics and statistical indicators of emerging industry cannot be obtained, in order to establish priority target industries, we selected towns as an emerging industry specialized to represent the Guangdong Province. This paper selected 82 specialized town to study emerging industries, including 15 of new electronic information industries, 4 of the semiconductor lighting industries, 3 of biopharmaceutical industries, 24 of new materials industries, 20 of energy saving industries, 8 of ocean industries, 5 of logistics industries, and 3 of the electric car industries. And the competitiveness of those industries is evaluated in respect of technology, economic, knowledge, hardware, software. Each emerging industries corresponding specialized town listed in Table 1 below, the data of this paper are mainly from the master's thesis of $\mathrm{Ou}$ (2011).

In order to analyze data easily and ensure comparability of data, this paper uses the data after standardization process. After principal component analysis, with the correlation coefficient matrix variables, Bartlett sphericity test and the KMO test method analysis, and then using varimax factor rotation method; after scores calculated by regression, come to the competitiveness scores of emerging industry specialized town in behalf of the Guangdong Province in technology, dimension, economic and knowledge, hardware, software. Part of the evaluation ratings in the following Table 1.

Table 1. Part of the evaluation ratings

\begin{tabular}{lll}
\hline Industry code & Specialized towns & Technological B1 \\
\hline B1 & Nanhai Luocun office & 4.6305 \\
B2 & Technology innovation town(Lighting specialized) & 17.2969 \\
B1 & Nanhai Luocun office & 0.9292 \\
B2 & Technology innovation town(Lighting specialized) & 2.5413 \\
B1 & Nanhai Luocun office & 8.5484 \\
B2 & Technology innovation town(Lighting specialized) & 0.4586 \\
B1 & Nanhai Luocun office & 30.9987 \\
B2 & Technology innovation town(Lighting specialized) & 19.5521 \\
B1 & Nanhai Luocun office & -5.1508 \\
B2 & Technology innovation town(Lighting specialized) & 54.7844 \\
\hline
\end{tabular}

\subsection{Construction of Emerging Industry Optimization Model Based on AHP-TOPSIS}

According to the collating the evaluation index score above the industry classification and sorted by industry, and we obtained the average of each industry evaluation of the corresponding five scores, and regard it as a evaluation index industry ratings, data processing are shown in Table 2 below.

Table 2. Part of the evaluation index ratings

\begin{tabular}{llllll}
\hline & Technology & Economic & Knowledge & Hardware & Software \\
\hline Semiconductor lighting & 14.9020 & 3.7375 & 23.5998 & 21.5041 & 28.8162 \\
Electric car & 2.4628 & 7.6561 & 30.7075 & 35.9077 & 19.2159 \\
Ocean & 5.3080 & -0.8347 & 7.1954 & 0.9252 & 24.8552 \\
Energy saving & 4.7008 & -0.2256 & 3.1754 & 1.9334 & 30.4525 \\
New materials & 9.9429 & 5.4690 & 11.2848 & 5.0094 & 40.2326 \\
Biopharmaceutical & 4.0754 & 1.1840 & 15.9889 & 3.3760 & 32.7944 \\
Logistics & 21.9670 & 0.4058 & 28.3425 & 28.2972 & 40.2564 \\
New electronic information & 27.7382 & 19.0139 & 12.5544 & 13.1338 & 54.1710 \\
\hline
\end{tabular}

According to the shown data, to horizontal comparison, the composite score of semiconductor lighting industry in technological is 14.9020, in terms of economic composite score for 3.7376, on knowledge integrated score for 23.5998, the composite score of hardware for 21.5042, software composite score for 28.8163 . In the 
semiconductor lighting industry, software support is the most competitive relative to other index. Similarly we can see, in the electric vehicle industry, the most competitive is hardware support; in the marine industry, the software support is the most competitive; in the energy-saving and environmental protection industry, the software supports is the most competitive; in the new materials industry, the most competitive is knowledge efficiency ; in the biopharmaceutical industry, software support is the most competitive; in the logistics industry, the software support is the most competitive; in the word of new electronic information industry, software support is the most competitive. To longitudinal comparison, in aspect of technology, economic, software support, new electronic information industry is the most competitive; in respect of knowledge and hardware support, the electric car industry's the most competitive.

\subsubsection{Determination of the Weight of Evaluation Index}

This paper uses AHP method to determine the weight. At first, we built the judgment matrix. Its judgment matrix shows the interaction relationship among the indexes. Each row of the determine the matrix A represents technology, economic, knowledge, hardware, software.

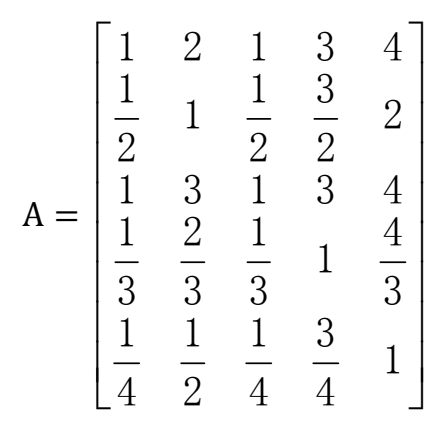

The column vector $\omega=(0.315,0.158,0.343,0.105,0.079)$ obtained by A. Corresponds of above consistency ratio $\mathrm{CR}=0.0218$, is less than 0.1 , which is indicating the consistency of judgment matrix is acceptable. Finally, the obtained weights of five indicators are shown in Table 3 as follows (technology W1, economic W2, knowledge W3, hardware W4, software W5).

Table 3. Weights of five indicators

\begin{tabular}{ll}
\hline Index & Weights \\
\hline Technology W1 & 0.315 \\
Economic W2 & 0.158 \\
Knowledge W3 & 0.343 \\
Hardware W4 & 0.105 \\
Software W5 & 0.079 \\
\hline
\end{tabular}

According to shown table, the share of knowledge is 0.343 , which plays a bigger role in those five indicators. The second one is technology, which proportion is 0.315 . The others, economic, hardware, software support is $0.158,0.105$ and 0.079 . It is obvious the technology and knowledge will bring to the industry more competitive in the evaluation of the emerging industry competitiveness.

\subsubsection{Positive and Negative Ideal Solution of Evaluation System Based on TOPSIS Method}

After determining the weight of the evaluation index, we can obtain a weighted average score on the competitiveness of emerging industries according to previous data. And we calculate the positive and negative ideal solutions of emerging industries and the extent of closing to the positive and negative the ideal value through using a weighted score based on the results of TOPSIS. Because the data is standardized by the AHP method, it can directly use into the calculations. Some results are shown in Table4 as follow. 
Table 4. Positive and negative ideal solutions of emerging industries

\begin{tabular}{llll}
\hline \multicolumn{1}{c}{ Industry } & $\mathrm{d}+$ & $\mathrm{d}-$ & $\mathrm{D}$ \\
\hline Semiconductor lighting & 13.3668 & 11.6506 & 0.4657 \\
Electric car & 17.8366 & 7.1346 & 0.2857 \\
Ocean & 24.632 & 17.3422 & 0.4131 \\
Energy saving & 25.5206 & 14.1251 & 0.3562 \\
New materials & 19.3319 & 24.2200 & 0.5561 \\
Biopharmaceutical & 21.1692 & 12.3895 & 0.3691 \\
Logistics & 9.4072 & 18.3837 & 0.6614 \\
New electronic information & 12.9417 & 27.2815 & 0.6782 \\
\hline
\end{tabular}

The table shows that, D8 $>$ D $7>$ D $5>$ D $1>$ D $3>$ D $6>$ D4 $>$ D2. The positive and negative solutions of new electronic information industry are most close to the ideal solutions. The second one is logistics industry. The extend closeness of electric car industry is weakest. In addition, The fact, which refers to the difference of maximum value and minimum value is 0.3925 , indicates differences of closeness extend between emerging industries in Guangdong Province are a bit big. The closer to the extent, the more competitive to the industry, we can see the greater the dominant development of emerging industries in Guangdong. The above results indicate that in terms of industrial competitiveness, new electronic information is the strongest, followed by the logistics industry, new materials industry, semiconductor lighting, marine industry, bio-pharmaceutical industry, energy saving industry, the weakest is the electric car industry. Therefore, we should give priority to the development of more competitive new electronic information industry, logistics industry, new materials industry, semiconductor lighting industry.

\subsubsection{Situation Analysis of Emerging Industries in Guangdong Province}

In 2014, the strategic emerging industries in Guangdong Province continued the good trend of steady development and enhanced overall strength. Also the industries continued to expand the scale and it is powerful impetus to the province's economic growth. In 2014, the strategic emerging industries added value of 317.771 billion yuan in Guangdong, $8.1 \%$ over the previous year. The province's industrial market share is $12.4 \%$, and industrial sales output value is $1,266,740,000,000$ trillion yuan, which is an increase of $10.5 \%$.

From the perspective of industrial scale, new electronic information industry, bio-industry, energy saving industry and energy saving industry, new materials industry and semiconductor lighting industry have achieved large value of total industrial added value. The industrial added value, are 119.638 billion yuan, 88.84 billion yuan, 32.268 billion yuan, 27.633 billion yuan, 25.768 billion yuan, the shares are respectively $37.6 \%$, $28.0 \%$, $10.2 \%, 8.7 \%, 8.1 \%$, the size of the province industrial added value accounted for $4.7 \%, 3.5 \%, 1.3 \%, 1.1 \%, 1.0 \%$. Specific data are shown in Table 5.

Table 5. Output value of emerging industries in Guangdong province in 2014

\begin{tabular}{|c|c|c|c|c|}
\hline \multirow[b]{2}{*}{ Industry } & \multicolumn{2}{|c|}{ Total output value } & \multicolumn{2}{|c|}{ Increase value } \\
\hline & $\begin{array}{l}\text { Absolute } \\
\text { Billion yuan }\end{array}$ & Growth(\%) & $\begin{array}{l}\text { Absolute } \\
\text { Billion yuan }\end{array}$ & Growth(\%) \\
\hline Total & 13125.03 & 10.9 & 3177.71 & 8.1 \\
\hline 1. New electronic information & 5446.39 & 10.1 & 1196.38 & 9 \\
\hline 2. Electric car & 61.79 & 4 & 16.27 & 6.7 \\
\hline 3. Semiconductor lighting & 1300.04 & 7.4 & 257.68 & 5.6 \\
\hline 4. Biopharmaceutical & 2613.98 & 16.5 & 888.4 & 9.9 \\
\hline 5.High level equipment manufacture & 918.5 & 9.3 & 211.56 & 6.2 \\
\hline 6.Energy saving & 1466.01 & 6.3 & 322.68 & 3.7 \\
\hline 7. New resource & 470.67 & 7.7 & 112.24 & 4.1 \\
\hline 8. New material & 1351.54 & 10.9 & 276.33 & 7.2 \\
\hline
\end{tabular}

From the growth perspective: in 2014, the province's strategic emerging industries grew faster in bio-industry and new electronic information industry, were up $9.9 \%$ and $9.0 \%$. The growth rate of new materials industry, new electric car industry and high-level equipment manufacturing industry is more than $6.0 \%$. 
Seen from above data, new electronic information industry's growth rate is $10.1 \%$, which contribute to the growth of emerging industry. The new materials industry's rate is $10.9 \%$, it is the largest contribution to GDP growth for the emerging industry's. New electronic information industry and new material industry are the most competitive in the industry development in Guangdong Province. Semiconductor lighting's growth trend is also best with the rate of $7.4 \%$. The present situation of development of emerging industries in Guangdong Province is consistent with optimization using AHP-TOPSIS model. The fact indicates that AHP-TOPSIS model came to the conclusion on applicability of strategic industry development of Guangdong Province. Development situation of new electronic car are at the end of the development of emerging industries, which is probably in Guangdong province for the development of new energy vehicles such as electric vehicles, has just started, compared with other fast-growing industries are still in a relatively backward position. As times goes on, the competitiveness of new electronic car may be creeping up. To sum up, in order to continue to improve the speed of development and promote development of emerging industries in Guangdong Province, we should vigorously develop more competitive industries such as new electronic information industry, new materials industry, semiconductor lighting.

\section{Conclusion}

Since 1898, Guangdong's GDP in 30 provinces and cities in China, continuously occupy the first. Guangdong Province has become the biggest economic province of China, accounting for $1 / 8$ of the total economy output, and beyond Hong Kong and Taiwan, and has reached the upper-middle-income countries, of moderately developed countries. In 2014, Guangdong provincial government published the "Guangdong strategic emerging industries the twelfth five-year plan" on the website, indicating that total 148 new industrial projects will be built with a total investment of 388.588 billion yuan. Among them, the provincial finance in the "five" period, will invest 22 billion yuan to support centralized strategic emerging industries. So it is very necessary to study on the optional selection to develop the emerging industry in Guangdong province.

Based on the AHP-TOPSIS method, this paper researched the evaluation and optimization of multiple strategic emerging industries in Guangdong Province. At the time of using the AHP method, we consider the expert opinions and the objectivity required of the data itself, and chooses data types based on previous researches, in order to achieve the TOPSIS method to calculate the error reduction.

First of all, based on past research, this paper identified five indicators for the evaluation of industry competitiveness, namely, the technological innovation dimension, economic efficiency, knowledge efficiency, hardware support and software support. These five areas are the important factors affecting the competitiveness of industries. Then the paper used the Delphi method to determine matrix to be used by the method of AHP judgment. And according to the judgment matrix, we obtained weight vector, the proportion of scores in the competitiveness in the industry is acceptable after consistency checking. Then the emerging industries of total index scores are weighted to be preferential. Using the industry's overall competitiveness rating by TOPSIS method, we calculated the positive values, negative values, and the closeness extent. Compared with each emerging industries, in Guangdong Province, there is a new electronic information industry, new materials industry and semiconductor lighting industry. Finally, emerging industry development's present situation investigation and analysis of Guangdong Province in 2014 has shown that new electronic information industry and new materials industry, semiconductor lighting industry are ranking top 3. It coincides with the results obtained in this paper. Therefore, we concluded we should give priority to the development of new electronic information industry, new materials industry and semiconductor lighting industry in Guangdong Province,

This paper used the AHP-TOPSIS method from the technological innovation dimension, economic efficiency, knowledge efficiency, hardware support and software support as evaluation index of emerging industries in Guangdong Province. This research method in region-specific optimization of multi-level strategic emerging industries is of applicability, and it can adapt to the strategic emerging industries for the development of comprehensive evaluation and optimization.

\section{Acknowledgements}

The project of the college students' innovation and entrepreneurship training plan in Jinan university (national level) (No. 201510559060).

\section{References}

Guo, L. Q. (2011). Domestic about the new development and comments on strategic emerging industries in China. Social Science Journal, (1), 152-155.

He, N., Zhang, Y. B., \& Zhang, Z. (2014). Evaluation of Academic Level of Sci-tech Journals Based on Rough 
Set and TOPSIS. International Journal of Statistics and Probability, 4(1), 12. http://dx.doi.org/10.5539/ijsp.v4n1p12

Huang, C. L., \& Yoon, K. (1981). Multiattribute Decision Making: Methods and Applications (pp. 12-34). NY: Spring-Verlag.

Huang, Y. X. (2013). Study on the Development of Strategic Emerging Industries in the Central Resource-based Cities-Take Loudi as an Example. Journal of Hunan Institute of Engineering, 3, 10-14.

Li, L., \& Liu, Q. N. (2013). Science and technology innovation to promote Tian Jin strategic emerging industry development path of research. Tianjin Economy, 9, 9-11.

Lin, X. J. (2012). The development of and forming model research strategic emerging industries. China Soft Science, 2, 26-34.

Ou, L. F. (2011). The competitiveness research of emering industries in Guangdong provinces based on technology innovation. South China University of Technology

Qiao, F. L. A., Yang, J. B., \& Hou, Q. A. (2010). Research on selection and evaluation of new strategic industries in Liaoning Province. Journal of Shenyang University of Technology, 3, 268-273.

Su, H. Y. (2013). Research on Comprehensive Advantages Evaluation of Strategic Emerging Industry. Harbin University of Science and Technology.

Sun, W. (2011). Decisions Analysis of AHP in Strategic Emerging Industry Evaluation and Selection in Henan Province. Journal of Henan Institute of Engineering, 1, 45-48.

Wan, G. (2010). Grasp the global industry adjustment opportunity, cultivating and developing strategic emerging industries. Truth Seeking, (1), 28-30.

Wang, W., \& Lu, Y. U. (2013). Qiao P. Selection and Evaluation of Strategic Emerging Industries and Empirical Study_ Empirical Analysis on Qiqihar City. Science \& Technology Management Research, 22, 116-120.

Ya-Jing M. A. (2014). Research on the Development of Dalian Strategic Emerging Industry Based on SWOT Model. Journal of Changchun University, 1, 9-12.

Zhang, L. Q., Zheng, C. H., \& Yan, W. (2010). Evaluation of Strategic Emerging Industries Based on Grey Relational Analysis: Empirical Analysis on Biology and Medicine Industry. Mathematics in Economics, 27(3), 79-84.

Zheng, C. H., \& Yan, W. (2011). Assessment index system and evaluating model of strategic emerging industries. Studies in Science of Science, 5, 678-683.

Zheng, C. H., Zhang, X., \& Zhou, Z. (2010). The Study of Strategic Emerging Industries' Selection System and Model. Science of Science \& Management of $S \& T, 12,62-67$.

Zhou, J. (2012). Development and Distribution of Strategic Emerging Industries in China. Statistical Research, 9, 24-30.

Zhu, R. B., \& Liu, Y. (2010). The Nurture and Its Independent Innovation of the Strategic Emerging Industry. Chongqing Social Sciences, (2), 45-53.

\section{Copyrights}

Copyright for this article is retained by the author(s), with first publication rights granted to the journal.

This is an open-access article distributed under the terms and conditions of the Creative Commons Attribution license (http://creativecommons.org/licenses/by/3.0/). 